\title{
Domestic Violence Against Self-Reliant Elderly Resulting from COVID-19 and Potential Solutions
}

\section{Ludvigh Cintulova (Lucia Ludvigh Cintulova)ํ․ G. Kafkova (Georgina Kafkova)²}

${ }^{1}$ St. Elizabeth University of Health and Social Sciences, Slovakia.

${ }^{2} \mathrm{MSF}$ and SERUC Program Freetown, Sierra Leone.

\section{E-mail address:}

luciacin83@gmail.com

\section{Reprint address:}

Lucia Ludvigh Cintulova

St. Elisabeth University of Health and Social Sciences

Nam. 1. Maja 1

81000 Bratislava

Slovakia

Source: Clinical Social Work and Health Intervention

Pages: $57-64$

Volume: 11

Issue: 3

\section{Reviewers:}

Vlastimil Kozon

University Hospital, Vienna, Austria

Daria Kimuli

St. Philippe Neri School, Joshka Nairobi, Kenya

\section{Keywords:}

Domestic Violence. Self-sufficient Elderly. Intergenerational Violence. Partner Violence. Relationship with the Violence Perpetrator. Practices and Experience.

\section{Publisher:}

International Society of Applied Preventive Medicine i-gap

CSWHI 2020; 11(3): 57 -64; DOI: 10.22359/cswhi_11_3_09 (C) Clinical Social Work and Health Intervention

\section{Abstract:}

During the current situation of the coronavirus outbreak there is an increase in anxiety levels due to isolation and disagreement with the restrictions on one's living space as well as many other crisis circumstances that cause an escalation in domestic violence against self-sufficient elderly. This issue is discussed to a lesser extent compared to domestic violence against the elderly who depend on others' assistance. In the case of selfsufficient elderly, perpetrators of domestic violence can also use the coronavirus pandemic to further weaken the self-sufficient elderly via misinformation that the perpetrators pass on to the elderly. Such misinformation then compels the elderly to act pursuant to the demands of the violence perpetrators. The 
perpetrators may use the following means for this purpose: prevent the elderly from having any access to information, telephone, or computer so that the elderly cannot call for help if necessary. Intervention centers that deal in depth with domestic violence against the elderly are a potential solution for the threatened elderly. The presented contribution focused on mapping the procedures, situations, and problems often encountered by the intervention center workers who help the elderly threatened by domestic violence; on the necessary skills of the workers; on their recommendations.

The obtained results can be applied when creating similar analyses that will serve as the basis for research which it is possible to build on even during the period of COVID-19 or similar epidemics.

\section{Introduction}

We can see that the ,present-day society appears to be very selfish and individualistic"(14) and its future and ,lifespan is neither pre-defined nor pre-determined in any way"(13), especially in the current situation of the COVID-19 pandemic. Individuals in community groups ,feel spiritual needs that are focused on transcendent values, as a need never stands on its own; instead, it signifies there is a lack of values" (20). Due to isolation and the ensuing loneliness, people long for relationships and, as a result, they strive for unity and appreciate their health all the more (20). Within them, there is ,, a new inner space in which they can accept themselves, whether beloved or broken“ (16). In this space, they have the opportunity to reflect more deeply on themselves, on positive and negative aspects of their personalities; to realize which areas in their lives still need to be developed and improved, and to reorganise their own lives (16) and thus ,in their inner freedom and with humility accept the truth about themselves“ (16). In this context, it is also necessary to reflect on the aspects of ,existential frustration or the absence of a clear answer to the fundamental questions of life's purpose and life's limited duration" or the opportunities for self-fulfilment of the elderly and their belief in their own usefulness (15). We need to ponder on these principles at professional and non-professional levels and look at them as two essential concepts that „sooner or later become important to everyone's life when they become part of their life“ (15).

As people grow older and weaker, they con- sider family to be increasingly more important in a number of aspects. In the case of the elderly, the social and material aspects are very significant. These aspects also include the financial situation of the elderly. Their retirement pension is one of the very relevant causes of domestic violence and has greater far-reaching consequences than a more superficial view might suggest. Given the amount of their pension, it is understandable that many elderly welcome the possibility of sharing a household. This, however, often represents a threat in the form of intergenerational tension. As many practical cases show, the perpetrators of domestic violence and aggression are not only blood relatives but also members of the extended family, including brides or sons-in-law, surprisingly enough. However, they often carry out acts of violence subtly and it is more difficult to detect them. In general, tension and violence in a household may be caused due to different intergenerational views and attitudes in life, personality traits or dispositions of the individual members of the household. During the current situation of the coronavirus outbreak, such causes include: anxiety from isolation and disagreement with the restrictions on their living space which occur mainly in the older household members. Perpetrators of domestic violence can also use the current coronavirus pandemic to further weaken the self-sufficient elderly via misinformation that the perpetrators pass on to the elderly. Such misinformation then compels the elderly to act pursuant to the demands of the violence perpetrators. The perpetrators may use the following means for this purpose: prevent the elderly from having any access to information, telephone, or computer so that the elderly cannot call for help if needed.

„Various forms of fear and concerns focused on the future" also contribute to the escalation of 
tension in a shared household (20). These may include, for example, fears of job loss, of the economic, social, and general life situation, of ,what the future holds", etc. In addition, they include various socio-pathological influences; the presence of long-term substance or non-substance addictions; financial; health-related; psychological problems of perpetrators of domestic violence; problems related to housing; employment problems; problems caused by unsuccessful marriages and many other life complications.

The most common victims of domestic violence are single mothers or elderly fathers aged 50 and upwards who are threatened by their sons, daughters, grandchildren, sons-in-law, or brides due to the consequences of the aforementioned addictions or unresolved property matters and related disputes. The aforementioned groups of domestic violence perpetrators often take advantage of parents' love and willingness to help them in their life situations and the perpetrators subsequently blackmail them. When the perpetrators are the offspring of the victim, their grandchildren, wife, or sons-in-law, they often use public opinion as an argument in their blackmailing should the elderly plan on reporting violence since many elderly people still place great emphasis on public opinion. As Robert Schreiter the American missiology professor and renowned international expert on non-violence and reconciliation - often says that such maliciousness caused by violence, trauma, and oppression must be overcome (19).

Intervention centers that deal with domestic violence against the elderly in depth are a potential solution for the threatened elderly. For example, in the Czech Republic, it is possible to find at least one center in each region specializing in helping the elderly who are experiencing domestic violence. Intervention centers generally provide victims of domestic violence with comprehensive counselling services consisting of legal, socio-legal, and psychological assistance to the elderly threatened by domestic violence in close cooperation with the police and other institutions. The intervention centers' obligation under the law is to provide assistance to the threatened elderly within 48 hours of receiving a copy of the police record. If the elderly agrees to cooperate with the center, he/she will receive a psychological intervention and key information. The inter- vention center workers then investigate whether the elderly has understood the police information; has been given appropriate protection; feels secure. Once this is clarified, the employees continue to provide the elderly with counselling services and coordination of other services. The services provided by intervention centers consist of social therapy activities and assistance in exercising rights and legitimate interests, in the making of personal arrangements, and they are provided as the outpatient, field, and residential services. Intervention centers can also be contacted in an informal way by the elderly or someone in their vicinity who noticed signs of threats, such as neighbors, acquaintances, or friends who then receive valuable advice and information for further action to ensure the elderly is provided with effective assistance. The intervention centers assess the family situation to see if this is indeed a case of domestic violence; provide an overview of legal services and other available options in the vicinity of the elderly's place of residence and inform him/her of all cooperation alternatives. In addition to caring for the elderly, the intervention centers also focus on coordinating information between cooperating institutions within the framework of interdisciplinary cooperation and on educating the relevant professions, which include, for example, policemen, social workers, carers, etc. Intervention centers, due to being the easiest to access by the elderly, either operate in other cities within a region during specific days of the month specified by the region or visit individually those elderly people who for some reason have more difficulties in accessing the center.

\section{Methods and Results}

In the period between December 2019 - February 2020 , we used qualitative research strategies to focus on mapping the procedures, situations, and problems often encountered by the intervention center workers who help the elderly threatened by domestic violence, on the necessary skills of the workers, and their recommendations. For this purpose, consultations with several center workers within the regions of the Czech Republic were carried out. In order to participate in the survey, the respondents had to meet the following conditions: be over 18 years of age and have long-term experience working with the elderly in intervention centers. Fifty respondents 
selected by a random sampling method participated in the survey. Upon conducting the survey, we evaluated which aspects are common in these centers. The obtained results can be applied when creating similar analyses that will serve as the basis for research, which it is possible to build on even during the period of COVID-19 or similar epidemics. The results may be viewed as a relevant insight to a certain level, even despite the fact that to some extent, the shorter survey period and its implementation on a smaller sample of respondents may be considered the survey's limiting factor.

Based on consultations and the conducted survey, we have demonstrably found that in intervention centers focused on helping the elderly threatened by domestic violence, intergenerational violence and a negative stance towards the application of legal remedies prevail. The reason is the justification of the actions of the violence perpetrator; the effort to minimize the perpetrator's violence; fear and shame in disclosing domestic violence; rapid onset of resignation; many elderly people fear that they will not be able to cope with their situation and want an institution or authority to solve it for them. They assume that if an authority speaks to the perpetrator of the violence, he/she will be ashamed, change their behavior, and their living together will become bearable. In such cases, it is necessary to patiently explain to the elderly that such a conversation is not effective because the perpetrators in most cases do not admit to themselves that they are behaving badly. Therefore, they have no reason to change their behavior and most likely, such conversation will later turn against the threatened elderly. The elderly also tend to associate violent behavior only with forms of violence, for example in the case of economic violence, the elderly justifies the violence by saying that if he/she accommodates the perpetrator, the violence will cease or, conversely, that the violence started precisely because he/she did accommodate the perpetrator; the same happens in psychiatric cases, diagnoses or narcotics.

Another frequently occurring type of violence that intervention center workers come into contact with is partner violence at an older age. In this case, defending oneself is hindered by the fear of the consequences of a divorce, because a person's divorce, especially at an older age, rep- resents a life burden which puts him/her in a kind of vacuum and also raises existential concerns (14). An associated complication in this regard is the fact that the elderly threatened by domestic violence by their spouse consider marriage to be „better in terms of ensuring the conditions for interesting activities [and] it is relatively better in a cohabitational relationship regarding sufficient time for inter-familial relationships“(2). During consultations and surveys, the intervention center workers also told us that, in the case of a marital or partner relationship at an elderly age, there is a more frequent incidence of males being the victims compared to other types of elderly abuse.

As in the case of intergenerational and partner domestic violence, a split relationship with the perpetrator of violence prevents the elderly from effectively resolving the situation. The elderly are often affected by self-blame for failing as a parent, for example. In this case, intervention center workers must also work with the threatened elderly on the "inner issue of forgiveness" (20). „This goes both ways: The first is the direction from oneself to other people; that is, active forgiveness where a family member with accusatory and self-accusatory tendencies tries to forgive himself/herself; other people; and perhaps even God for ,what has befallen" him/her. Passive forgiveness, as ,the other side of the coin“, means the suffering parent accepts others' forgiveness which consists of being unconditionally accepted by those around him/her. The parent is not blamed for a situation for which he/she is objectively not responsible; and he/she is also not unnecessarily reminded of actions for which he/she is actually responsible" (20). Such forgiveness does not mean that the past is forgotten or overlooked. We will continue to remember this, but in different ways that do not involve anger and resentment (8). At the same time, it is necessary to work on detaching the elderly from the perpetrators of violence because for many of them the idea of losing a loved one - despite all the violence they have committed, they are still loved is unimaginable. The fear of loneliness is stronger than fear for one's own health or life. In accompanying the elderly, intervention center workers must ,honor the resources for rebuilding and integration that are part of [their] worlds" (18). In this context, gestures are important to help the elderly restore a sense of routine and ,se- 
cure boundaries to keep out harm [...] in physical as well as symbolic ways"(17). To prevent health problems, restoration of bodily integrity during such accompaniment is as important as ,dealing with the psychological issues to be addressed“ (17). The intervention center workers provide the threatened elderly with a form of assistance and support that helps them cope with the situation while relying on the gradual mobilization of the elderly person's own internal resources (16). This includes a particular dimension, i.e. offering another person the gift of one's own presence and time. What that means is that, one does not offer solutions or advice applicable to the other person's situation; instead, one simply stays with the other person in silence and under all circumstances" (10). This gift of presence can also be applied by intervention center workers, for instance, ,in situations where it is difficult for the [threatened elderly] to express words of consolation“. In cases like these, words ,lose their meaning and the mere presence of another human being can be helpful" (10).

In order to be able to ensure all these aspects for the threatened elderly, the experience of the intervention center workers reveals that all contact with the violence perpetrator must be avoided. Continuous contact may destroy all previous progress and lead to an assault. If it is not possible to avoid mutual communication, it should take place in a safe environment and the presence of another person or entrust the communication to a trusted person or a lawyer, for example. In this context, it is also necessary to help the elderly create a broad network of friends, family, neighbors or professionals consisting of psychologists, social workers and intervention center workers who will continue to work with the threatened elderly on the process of forgiving and disengaging from the perpetrator of violence.

During the consultations, we also asked workers working in intervention centers aimed at helping the elderly threatened by domestic violence about specific skills that they must apply in practice.

First of all, they must be internally capable of being helpful, being available and being close to the threatened elderly who expect help from them and need not only their human but also professional approach (16). The elderly also need their company with the opportunity of establishing a healthy assisting relationship (16). Therefore, it is necessary for them to master the skills of effective communication; to have well-established critical thinking; appreciation of their activities (11); to be able to provide strong and well-organized assistance to those elderly ,who obviously cannot deal with their situation" or do not want to deal with their situation (5).

An important part of their work is also the creation of a supervisory system. It makes them „feel that they are emotionally „not alone“ in dealing with challenging situations they are confronted with on several occasions per day" (9). As a result of being, ,relieved of emotional stress and emotionally rested" they can continue to perform work duties (9). For them, it is an effective preventive measure against the burnout syndrome (9); in a fundamental way it also helps them work on their own development on a personal and professional level; this can ultimately help them achieve a higher quality of professionalism and effectiveness in the assisting process (7).

Intervention center workers also talked about the procedures they use in practice in the event of an informal contact by a threatened elderly.

The first step is an initial assessment consultation which examines their family situation. Subsequently, the elderly is offered relevant services and advice. When communicating with the elderly it is necessary to adjust the speaking pace, intonation, volume, complexity and the amount of information provided in order to avoid information overload. If for some reason the police do not take any action in the elderly's situation, with the consent of the elderly, his/her case may be transferred to the relevant social department which may become more involved in the elderly's situation by paying him/her visits, for example.

In the second step, the emphasis is placed on creating a more detailed security plan because the elderly sometimes unknowingly provoke the perpetrator to carry out even worse attacks. If the threatened elderly nevertheless decide to deal with their situation drastically, the intervention centers help them overcome their fear of contacting the competent authorities. When contacting the police, the elderly often face obstacles in the form of negative experiences with the totalitarian regime, fear, and communication barriers due to 
their older age such as the impaired ability to describe a specific event. The intervention center workers, therefore, try to inform the elderly of what is important when testifying to the police and what is not. In the event of court proceedings, the elderly have the opportunity to be represented by a law firm with which the relevant intervention center cooperates contractually, therefore, the price for its services for the elderly is also symbolic.

Based on the statements of the intervention center workers, it is also clear that they are aware of their crucial role in awareness-raising activities, so they organize various courses for professions that may encounter domestic violence. They mentioned, for example, courses for medical university students; special courses for carers of the elderly aimed at recognizing and dealing with domestic violence. Their courses also include a special program for people who have trouble coping with aggression in relationships or are unable to cope with it at all. In their experience, this program could motivate the threatened elderly to mobilize themselves to deal with their situation. At the same time, however, the workers point out that the internal motivation of the perpetrators of violence, as well as the exclusion of the presence of any substance or non-substance addictions, are essential for the program to be successful. These specially-designed programs are also important because the trauma caused by domestic violence can be transferred from generation to generation either consciously (intentionally) or unconsciously (automatically) (8). „An example of such transfer can be seen in situations of domestic violence where the father's violent behavior is reflected in the violent behavior of his children in their own household once they become adults" (8).

\section{Discussion}

Even though the consultations with the workers were carried out prior to the spread of the coronavirus in the Czech Republic, they also pondered potential solutions in the event of a necessary isolation of the elderly. It is clear that the rate of domestic violence reporting will decline but it will continue to occur. The reason may also be the doubts of the elderly of whether someone will deal with or take seriously domestic violence during such a period. Therefore, it is necessary to look for solutions that would be helpful for the elderly and other people threatened by violence during the period of isolation, when the level of violence will naturally increase in the existing violent household environment. One potential solution is for the threatened elderly to build the aforementioned broad support network and agree with its members in advance on potential signals indicating that they feel threatened. The support network members would subsequently contact the relevant authorities. Another potential solution is, in cooperation with the individual selfgoverning regions, to research and study the challenges and possibilities or threats that could still affect the threatened elderly under certain conditions (13) and to work to create such alternatives that would also be helpful to the elderly who are in some way denied access to a telephone and information by the perpetrator of the violence.

Another important aspect presented by the intervention center workers is raising awareness and carrying out activities to promote a new intergenerational perception of the elderly which needs to be worked on at the societal level. The elderly help us see human affairs with greater wisdom because they acquired knowledge and matured as a result of life's hardships. They preserve our collective memory and thus serve as privileged interpreters of this set of ,ideals and common values which support and guide life in society. To exclude the elderly is in a sense to deny the past in which the present is firmly rooted in the name of a modernity without memory." As a result of their mature experience, the elderly may provide the young with valuable advice and guidance (15). It is also essential to strengthen all aspects of care for the elderly, including the issue of improving the quality of health care at the international level and the possibilities of its accessibility regardless of the geographical location or culture of the individual nations (12).

\section{Conclusion}

It is the elderly who are among the most vulnerable group that needs to be given increased attention even in the context of long-term care and various aspects directly or indirectly related to domestic violence against them. After detailed research and analyses, it will be possible to prepare, at least partially, for what the future may bring 
when working with the elderly as well as when caring for them. Science will most likely never be able to precisely predict future development (13). However, as we can see already in the midst of the current COVID-19 situation, the desire for reconciliation has increased significantly, handin-hand with the feelings of brokenness. Even in the fight against violence against the elderly, ,it represents the search for justice, the healing of memories, and the rebuilding of new relationships" (8). In the environment of intercultural communication, a new opportunity has arisen to eradicate racial, cultural, and other prejudices and thus prepare the ground for the reunification of humanity (3). Therefore, human effort must be directed towards the future while at the same time being focused on the problems in the present. Above all, however, such effort should serve as an act of hope (1) realized in patience, peace, balance in dialogue, and the promotion of human dignity (6). In this sense, when working with the elderly and even in the intervention centers, it is necessary to emphasize the deep and noble motivation of workers to provide assistance (...) because there exists no greater opportunity or responsibility, but also obligation, than that which is given to a person who helps people who depend on others' assistance (4).

\section{References:}

1. BARGAR P (2016) Concepts of theology of mission relevant today as discussed in significant missiological works. In Acta Missiologica, 201610 (2) p. 13. ISSN: 1337-7515 (Print) ISSN: 2453-7160 (On-line) https://www.actamissiologica.com/.

2. BEDNARIK R, ZUFFA J (2018) Selected value indicators of Slovak families. In Acta Missiologica, 201812 (2) p. 97. ISSN: 13377515 (Print) ISSN: 2453-7160 (On-line) https://www.actamissiologica.com/.

3. BUCKO L (2016) The current mission model applicable to today's globalized world. In Acta Missiologica, 201610 (2) p. 29. ISSN: 1337-7515 (Print) ISSN: 2453-7160 (Online) https://www.actamissiologica.com/.

4. CIESKO P (2016) Analysis of selected social elements relevant for current mission activities from the perspective of a social study of the church. In Acta Missiologica, 201610 (2) p. 40. ISSN: 1337-7515 (Print) ISSN: 2453-
7160 (On-line) https://www.actamissiologica.com/.

5. CZARNECKI P (2018) Social pedagogy, social policy and the system of care and social assistance - how to keep human dignity at the center of the discussion? In Acta Missiologica, 201812 (1) pp. 54, 55. ISSN: 1337-7515 (Print) ISSN: 2453-7160 (On-line) https://www.actamissiologica.com/.

6. DIAN D (2016) Christian social study, ecumenism and the Eucharist. In Acta Missiologica, 201610 (1) p. 70. ISSN: 1337-7515 (Print) ISSN: 2453-7160 (On-line) https://www.actamissiologica.com/.

7. DAVIDOVA M, HARDY M, HAMAROVA M, (2017) Perception of meaningfulness and a safe type of relationship bond as an important means of assistance for helping professions. In Acta Missiologica, 201711 (2) p. 79. ISSN: 1337-7515 (Print) ISSN: 24537160 (On-line) https://www.actamissiologica.com/.

8. JASSO J (2016) Recommendations for mutual relations between the Greek-Catholic Church and the Russian Orthodox Church on Ukraine's territory following the application of the reconciliation process based on Robert Schreiter's concept. In Acta Missiologica, 201610 (2) p. 50, 65. ISSN: 1337-7515 (Print) ISSN: 2453-7160 (On-line) https://www.actamissiologica.com/.

9. KRALOVA Z, KUKLOVA D (2017) Volunteer works as a specific form of aid to refugees in refugee camps. In Acta Missiologica, 201711 (2) p. 29, 30. ISSN: 1337-7515 (Print) ISSN: 2453-7160 (On-line) https:// www.actamissiologica.com/.

10. MAES M (2019) Depictions of holiness in the modern poverty in the literary works of Christian Wiman and Willem Jan Otten. In Acta Missiologica, 201913 (1) p. 59. ISSN: 1337-7515 (Print) ISSN: 2453-7160 (Online) https://www.actamissiologica.com/.

11. MARKOVIC BALUCHOVA B, SVOBODOVA M (2016): The representation of vulnerable persons from developing countries and the poverty marketing methods used on the websites of select non-profit organizations. In Acta Missiologica, 201610 (1) p. 45. ISSN: 1337-7515 (Print) ISSN: 2453-7160 (On-line) https://www.actamissiologica.com/. 
12. NOVA M (2017) Particularities of professional and lay health care in South-Eastern Uganda. In Acta Missiologica, 201711 (1) p. 63. ISSN: 1337-7515 (Print) ISSN: 24537160 (On-line) https://www.actamissiologica.com/.

13. NOVACEK P (2016) The Rise and Fall of Civilizations - Lessons Learnt from History to Create a Sustainable Future. In Acta Missiologica, 201610 (2) p. 29. ISSN: 13377515 (Print) ISSN: 2453-7160 (On-line) https://www.actamissologica.com/.

14. PILER P (2016) The Influence of Urs Baumann on the Understanding of Partner Relationship and the Ethical Approach to Divorce. In Acta Missiologica, 201610 (2) p. 104, 108. ISSN: $1337-7515$ (Print) ISSN: 2453-7160 (On-line). https://www.actamissiologica.com/.

15. SMIDOVA M, TREBSKI, KA, NEMCIKOVA, M (2019) Quality in long-term care: Central European people-centered assessment principles and their calls for an efficient interdisciplinary dialogue. In Acta Missiologica, 201913 (2) p. 209, 210. ISSN: 1337-7515 (Print) ISSN: 2453-7160 (Online) https://www.actamissiologica.com/.

16. SMIDOVA M (2016) Preparation of volunteers engaged in helping professions and working with families in difficult situations. In Acta Missiologica, 201610 (2) p. 86, 88, 89, 90. ISSN: 1337-7515 (Print) ISSN: 24537160 (On-line) https://www.actamissiologica.com/.
17. SCHREITER R (2018) Dealing with trauma and the healing of memories. In Acta Missiologica, 201812 (1) p. 13. ISSN: 1337-7515 (Print) ISSN: 2453-7160 (On-line) https:// www.actamissiologica.com/.

18. SCHREITER R (2017) The distinctive characteristics of Christian reconciliation relevant for current mission activities. In Acta Missiologica, 201711 (1) p. 21. ISSN: 13377515 (Print) ISSN: 2453-7160 (On-line) https://www.actamissiologica.com/.

19. SCHREITER R (2016) Reconciliation as a mission model for the first half of the $21^{\text {st }}$ century. In Acta Missiologica, 201610 (1) p. 10. ISSN: 1337-7515 (Print) ISSN: 24537160 (On-line) https://www.actamissiologica.com/.

20. TOMICZEK V, SLANY J (2017) Spiritual Support for Families in the Context of Early Childhood Care. In Acta Missiologica, 2017 11 (1) p. 101, 102, 103. ISSN: 1337-7515 (Print) ISSN: 2453-7160 (On-line). https:// www.actamissiologica.com/. 